Review

\title{
Resveratrol and Calcium Signaling: Molecular Mechanisms and Clinical Relevance
}

\author{
Audrey E. McCalley ${ }^{1}$, Simon Kaja ${ }^{1}$, Andrew J. Payne ${ }^{1}$ and Peter Koulen ${ }^{1,2, *}$ \\ 1 Vision Research Center, Department of Ophthalmology, School of Medicine, \\ University of Missouri-Kansas City, 2411 Holmes St., Kansas City, MO 64108, USA; \\ E-Mails: aemqp4@mail.umkc.edu (A.E.M.); kajas@umkc.edu (S.K.); paynea@umkc.edu (A.J.P.) \\ 2 Department of Basic Medical Science, School of Medicine, University of Missouri-Kansas City, \\ 2411 Holmes St., Kansas City, MO 64108, USA \\ * Author to whom correspondence should be addressed; E-Mail: koulenp@umkc.edu; \\ Tel.: +1-816-404-1834; Fax: +1-816-404-1825.
}

Received: 16 April 2014; in revised form: 23 May 2014 / Accepted: 23 May 2014 /

Published: 5 June 2014

\begin{abstract}
Resveratrol is a naturally occurring compound contributing to cellular defense mechanisms in plants. Its use as a nutritional component and/or supplement in a number of diseases, disorders, and syndromes such as chronic diseases of the central nervous system, cancer, inflammatory diseases, diabetes, and cardiovascular diseases has prompted great interest in the underlying molecular mechanisms of action. The present review focuses on resveratrol, specifically its isomer trans-resveratrol, and its effects on intracellular calcium signaling mechanisms. As resveratrol's mechanisms of action are likely pleiotropic, its effects and interactions with key signaling proteins controlling cellular calcium homeostasis are reviewed and discussed. The clinical relevance of resveratrol's actions on excitable cells, transformed or cancer cells, immune cells and retinal pigment epithelial cells are contrasted with a review of the molecular mechanisms affecting calcium signaling proteins on the plasma membrane, cytoplasm, endoplasmic reticulum, and mitochondria. The present review emphasizes the correlation between molecular mechanisms of action that have recently been identified for resveratrol and their clinical implications.
\end{abstract}

Keywords: resveratrol; calcium; signaling; inflammation; pain; cancer; Alzheimer's disease; Huntington's disease; Parkinson's disease; and amyotrophic lateral sclerosis; cardiovascular disease; diabetes mellitus; autoimmune 


\section{Introduction}

\subsection{Effects and Mechanisms of Action of Resveratrol as the Basis for Its Therapeutic Potential in} Various Diseases

Resveratrol is a stilbenoid commonly found in the roots of Japanese Knotweed and the skin of red grapes. Plants produce phytoalexin as a response to harmful stimuli such as UV radiation, infection, or other pathogenic threats [1,2]. Increased curiosity about resveratrol and its potential health benefits began with a phenomenon termed the "French Paradox" [3] that became a fascination of health professionals and researchers. The "French Paradox" describes the extremely low incidence rate of cardiovascular disease in France compared with other European countries despite a high fat diet with little to no exercise [4]. Epidemiological studies indicated that polyphenols present in red wine could be responsible for the cardioprotective effects experienced by the French [4-6]. Resveratrol then initially became a subject of study for potential cardiovascular benefits but additional benefits are becoming apparent in recent studies [7]. Some of the proposed mechanisms include antioxidant, anticarcinogenic, anti-inflammatory, anti-aging [8], and anti-nociceptive functions indicating the potential of resveratrol as therapeutic agent for preventing and ameliorating a wide range of pathologies [9-14], including neurodegenerative diseases such as Alzheimer's disease (AD), Huntington's disease (HD), Parkinson's disease (PD), and amyotrophic lateral sclerosis (ALS) [8,15,16]. Cardiovascular diseases that may benefit from resveratrol treatment include hypertension, ventricular arrhythmia, myocardial infarction (MI) induced ventricular tachycardia, ventricular fibrillation, arteriosclerosis, arteriolosclerosis, and restenosis particularly after angioplasty [7,13,17-20]. In addition, cerebral ischemia, diabetes mellitus, cancer, autoimmune diseases, and other inflammatory-related issues have been discussed as potentially benefitting from resveratrol intervention [13,15,21,22]. Resveratrol also provides protection from UV radiation explaining its potential use in the prevention of age-related macular degeneration (AMD) $[23,24]$. Potential mechanisms underlying resveratrol's actions are its ability to control protein activity via interaction with transmembrane and intracellular enzymes [25].

\subsection{Key Signaling Proteins Controlling Cellular Calcium Homeostasis}

Resveratrol is a potent regulator of genomic and non-genomic processes including regulation of membrane potential, DNA transcription, enzyme activity, secretion, apoptosis, mitochondrial activity, and intracellular ion homeostasis, including the modulation of the intracellular calcium concentration $[3,7,25]$.

Resveratrol can act as a ligand for trans-membrane proteins [23] including voltage-gated calcium channels (VGCC) and plasma membrane calcium ATPase (PMCA) [26,27]. Intracellularly, calcium release activated channels (CRAC), sarco-/endoplasmic reticulum calcium ATPase (SERCA), and intracellular calcium channels (ICC) contribute to calcium ion homeostasis [28-32]. Resveratrol potentially increases endoplasmic reticulum (ER) calcium concentrations through modulation of SERCA but may also contribute to the decrease or stabilization of the release of calcium from intracellular stores by modulating ICCs [31,33-36]. Most importantly, there is significant evidence to conclude that resveratrol contributes to overall calcium homeostasis during states of cellular dysfunction [37]. While resveratrol does not exhibit cellular toxicity, mild systemic yet reversible 
gastrointestinal disturbances were detected when resveratrol was used for extended periods of time in high concentrations $[38,39]$.

\section{Medical Relevance of Modulation of Cellular Calcium Signaling Mechanisms by Resveratrol}

\subsection{Modulation of Cellular Calcium Signaling Mechanisms by Resveratrol in Excitable Cells}

Resveratrol potently modulates the intracellular calcium concentration in excitable cells through a variety of mechanisms that control calcium influx, store filling, release from intracellular stores, and downstream activation of calcium sensitive molecules. In myocytes, resveratrol increases the refractory period and decreases the threshold for membrane depolarization [17]. This results in restored calcium homeostasis evident by a reduction of delayed after depolarization (DAD, occurs with cytoplasmic calcium influx) and triggered activity (TA, ensues via irregular calcium release) in myocytes [37,40,41]. Resveratrol, therefore, can ameliorate cardiac arrhythmia and prevent premature atrial contraction (PAC) [17].

Similar membrane hyperpolarization in response to resveratrol also occurs in smooth muscle cells (SMC) leading to vasodilation, making resveratrol a candidate for the treatment of a wide variety of disorders including hypertension, ventricular arrhythmia, myocardial infarction (MI) induced ventricular tachycardia, and ventricular fibrillation $[18,41,42]$. Furthermore, it has been suggested that the ability of resveratrol to induce endothelium-dependent hyperpolarization of SMCs may compensate for pathologic absence or dysfunction of endothelium nitric oxide synthase (eNOS) and cyclooxygenase-1 (COX-1) [43]. Endothelial cells line the walls of the lymphatic and cardiovascular vessels and are critical modulators of contractility and vessel dimensions. Vasorelaxation is the most extensively studied effect of resveratrol on vascular endothelia. Most studies focus on two interlinked mechanisms of action, the direct effect on the intracellular calcium concentration and the downstream indirect effects on cellular potassium regulation [44]. A resveratrol dependent increase in nitric oxide biosynthesis was shown to result from calcium mobilization rather than direct agonism of eNOS by the drug [45]. The major plasma membrane targets of resveratrol include the L-type VGCC, which is directly inhibited by resveratrol, and the large conductance calcium-activated potassium (BK) channel, that resveratrol indirectly effects [19,37]. Under physiological conditions, calcium influx via L-type VGCCs stimulates BK channels that facilitate cytosolic potassium ion efflux, which results in membrane hyperpolarization. Resveratrol directly attenuates calcium influx, indirectly decreasing potassium efflux, and leading to a state of vasorelaxation in an endothelium-dependent manner $[20,46,47]$. Due to these effects, resveratrol may be beneficial in preventing or mitigating the physiological effects of hypertension, arteriosclerosis, arteriolosclerosis, and restenosis (particularly after angioplasty). Interestingly, diabetes mellitus is an important, clinically relevant risk factor for all four conditions [48].

In neuronal cells, resveratrol reduces the action potential threshold and both delays and prolongs calcium entry (Figure 1) [16]. This effect causes rapid sodium-induced action potentials that increase neuronal conduction. This mechanism of action has the potential to regulate and increase neural impulses which may provide a basis for the prevention of conductance disorders or to retard neurodegenerative processes. Resveratrol has also been shown to protect against cerebral ischemic 
damage via indirect BK channel activation, thereby preventing neuronal hyperexcitability and the ensuing cell death $[15,16]$. While resveratrol can prevent neuronal death and provide protection against oxygen-glucose deprivation [49,50], the potential of resveratrol for therapeutic intervention in axonopathy or other conduction block disorders remains to be elucidated [8,51]. The pleiotropic effects of resveratrol with its respective molecular mechanisms, and the pharmacological modulation of those mechanisms, affect separate components of membrane depolarization and repolarization, resulting in a distinct modulation of spatio-temporal properties of electrical signaling by resveratrol in excitable cells.

Figure 1. Resveratrol's mechanism of action in excitable cells. Resveratrol lowers the threshold and increases the duration of calcium influx in excitable cells $[16,17]$.

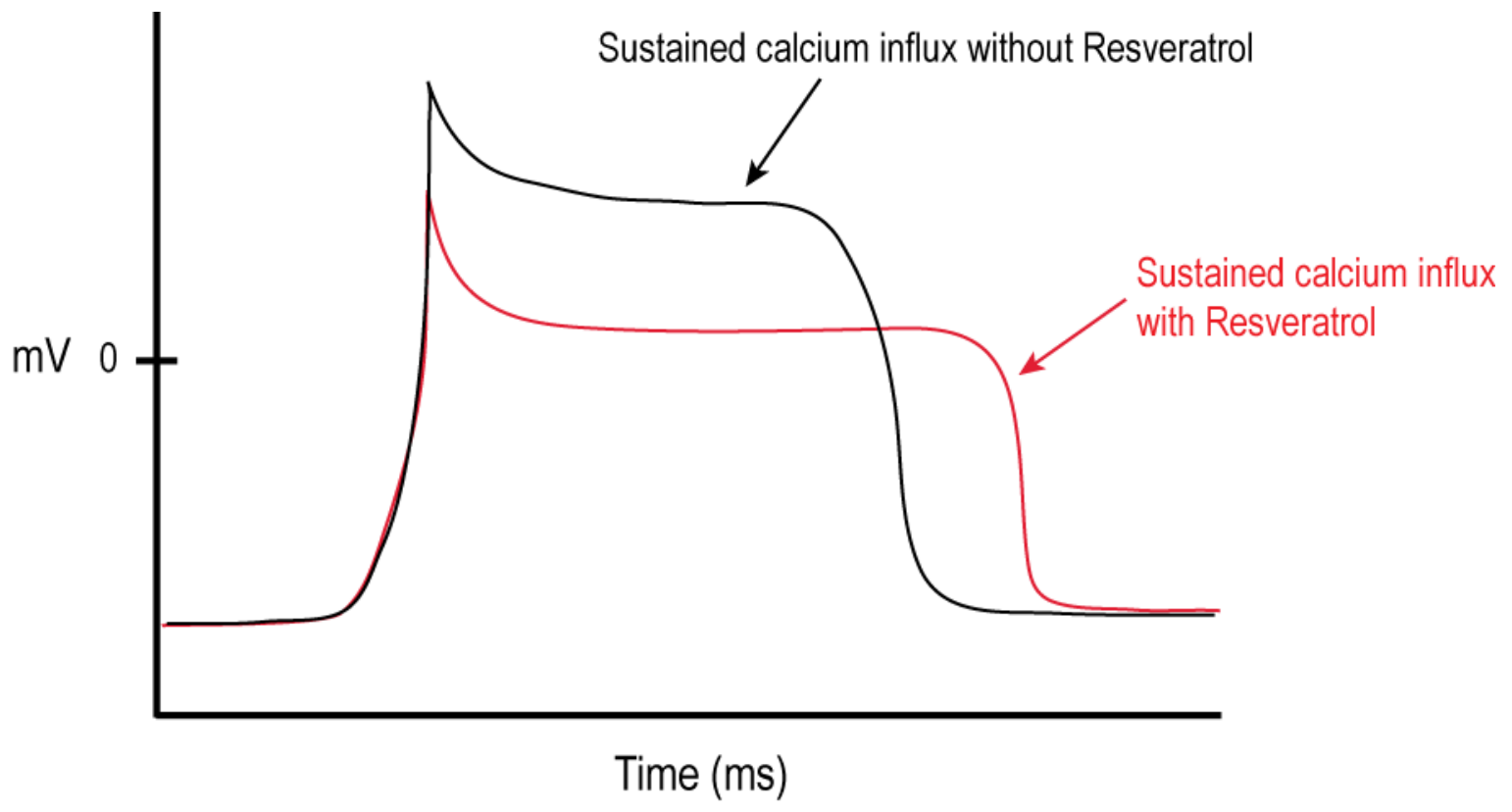

\subsection{Modulation of Cellular Calcium Signaling Mechanisms by Resveratrol in Cancer and Immune Cells}

Resveratrol shows great promise as a therapeutic agent for a variety of cancers [52]. Given its effects on calcium homeostasis, resveratrol may be useful as a latent remedy for the primary stages of some malignant cancers [53]. Calcium signaling pathways are necessary for the motility and invasive characteristics of malignant tumors, as it controls cell restructuring and dedifferentiation [54]. Another potential mechanism of action for resveratrol targets the excessive energy demand of tumor cells, lowers calcium thresholds, and prolongs intracellular calcium surges, all of which ultimately lead to cell death as a result of mitochondrial dysfunction [55]. Previously, resveratrol has been shown to suppress $\mathrm{CD} 4{ }^{+} \mathrm{CD} 25^{+}$regulatory $\mathrm{T}$ cells $\left(\mathrm{T}_{\text {reg }}\right.$ cells) in a preclinical cancer model [56]. $\mathrm{T}_{\text {reg }}$ are critical mediators of self-tolerance and inhibit the proliferation of $\mathrm{CD} 4{ }^{+} \mathrm{CD} 25^{-}$conventional $\mathrm{T}$-cells $\left(\mathrm{T}_{\text {con }}\right)$ through a recently identified mechanism involving the suppression of intracellular calcium release [57]. Further studies are needed to identify how resveratrol modulates intracellular calcium homeostasis during the early phases of tumor growth.

Resveratrol is a powerful modulator of the immune system response via both pro- and anti-inflammatory pathways [58,59]. Resveratrol has the ability to activate immune cells at low doses while exerting an inhibitory effect at high doses [21,52]. The mechanism of action of resveratrol in 
immune cells likely involves a combination of proteasome inhibition [60] and modification of the cytosolic calcium concentration through blocking calcium entry and increasing calcium storage [31]. It has been suggested that resveratrol can reversibly modify disturbed system responses such as mast cell granulation [56]. Resveratrol decreases mast cell hypersensitivity by reducing calcium influx thereby reducing granulation (Figure 2) [12]. Resveratrol has also been shown to decrease inflammatory responses in autoimmune disorders, such as multiple sclerosis, through potentiation of active T-cell apoptosis [56,61]. It appears that resveratrol exerts effect on intracellular calcium by modulating sequestration and release of intracellular stores but further studies are needed to elucidate the exact mechanism of action in lymphocytes and other cell types of the immune system.

Figure 2. Resveratrol attenuates immune responses related to degranulation.

Resveratrol decreases calcium influx, inhibiting granule release in mast cells $[14,58]$.

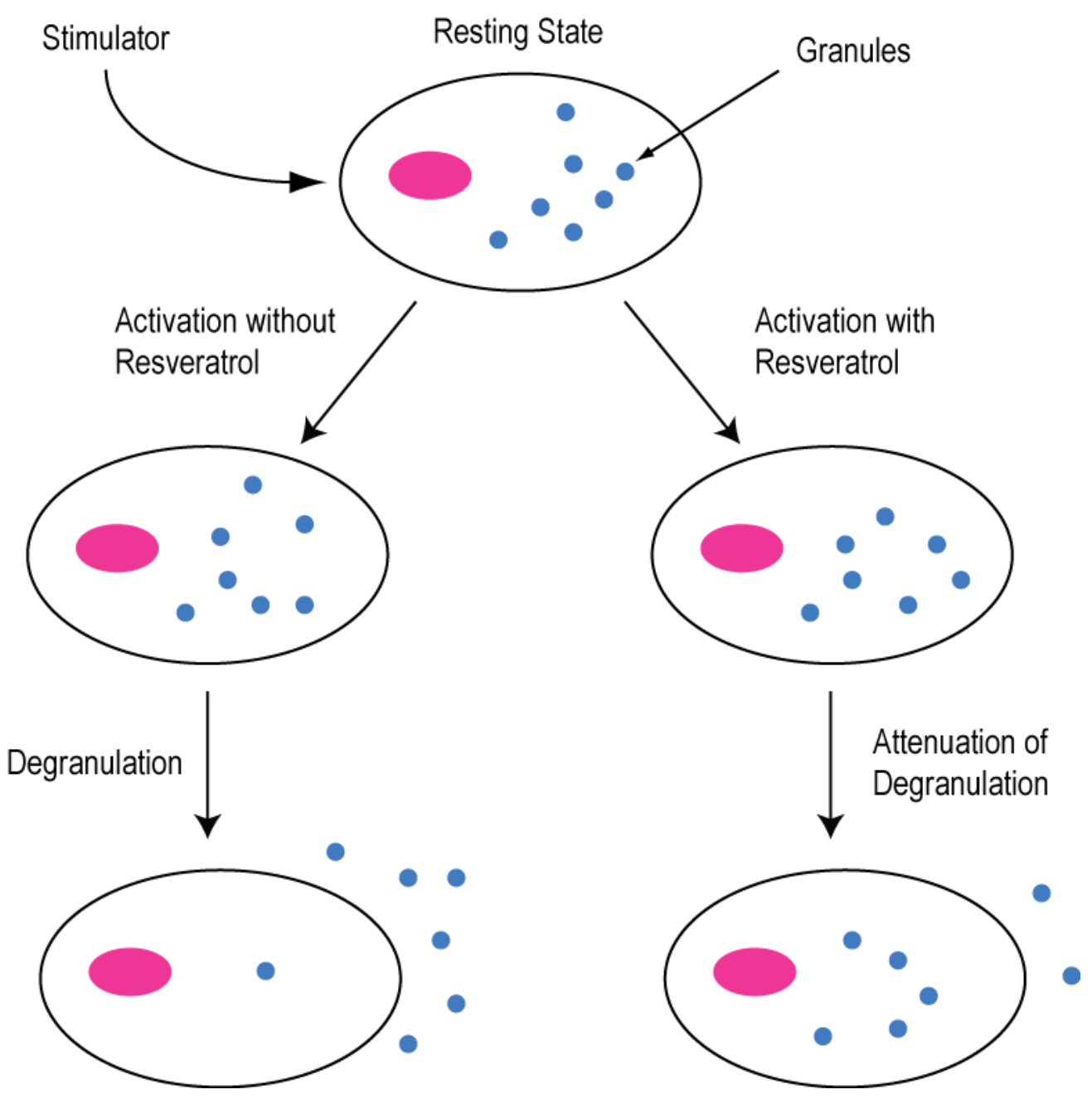

2.3. Modulation of Cellular Calcium Signaling Mechanisms by Resveratrol in Human Retinal Pigment Epithelial Cells

Trans-resveratrol is susceptible to photoisomerization to cis-resveratrol when exposed to ultraviolet irradiation [62]. When present in retinal pigment epithelial (RPE) cells, or any cell subject to UV ray exposure, resveratrol absorbs damaging UV light, thus reducing exposure of other structures to damaging wavelengths and ultimately enhancing the protective function of RPE cells (Figure 3) [23]. 
One key mechanism in RPE cells is phagocytosis, an important renewal mechanism that is susceptible to UV damage [23]. In experimental studies, resveratrol preserved RPE cell phagocytosis when applied prior to insult but had no protective effect when used as a post-insult treatment [23]. It has been proposed that this protective effect is mediated with BK channels [23]. Chronic resveratrol supplementation, rather than acute administration, would therefore be required for pharmaceutical intervention studies.

Another protection mechanism includes the anti-oxidative effect of resveratrol $[63,64]$. Pretreatment of RPE cells with resveratrol ameliorated the oxidative stress related damage caused by hydrogen peroxide by preventing oxidation related RPE phagocytic impairment, which may be linked to BK channel activity [23]. Furthermore, the clinical course of age-related macular degeneration (AMD), and potentially other vascular diseases of the retina, may be slowed by resveratrol when given as a nutritional additive $[24,65]$.

Figure 3. Resveratrol protects RPE cells from UV damage. Trans-resveratrol absorbs UV light and is converted to cis-resveratrol thereby preventing RPE cells from the deleterious effects of UV damage [23,62-64].

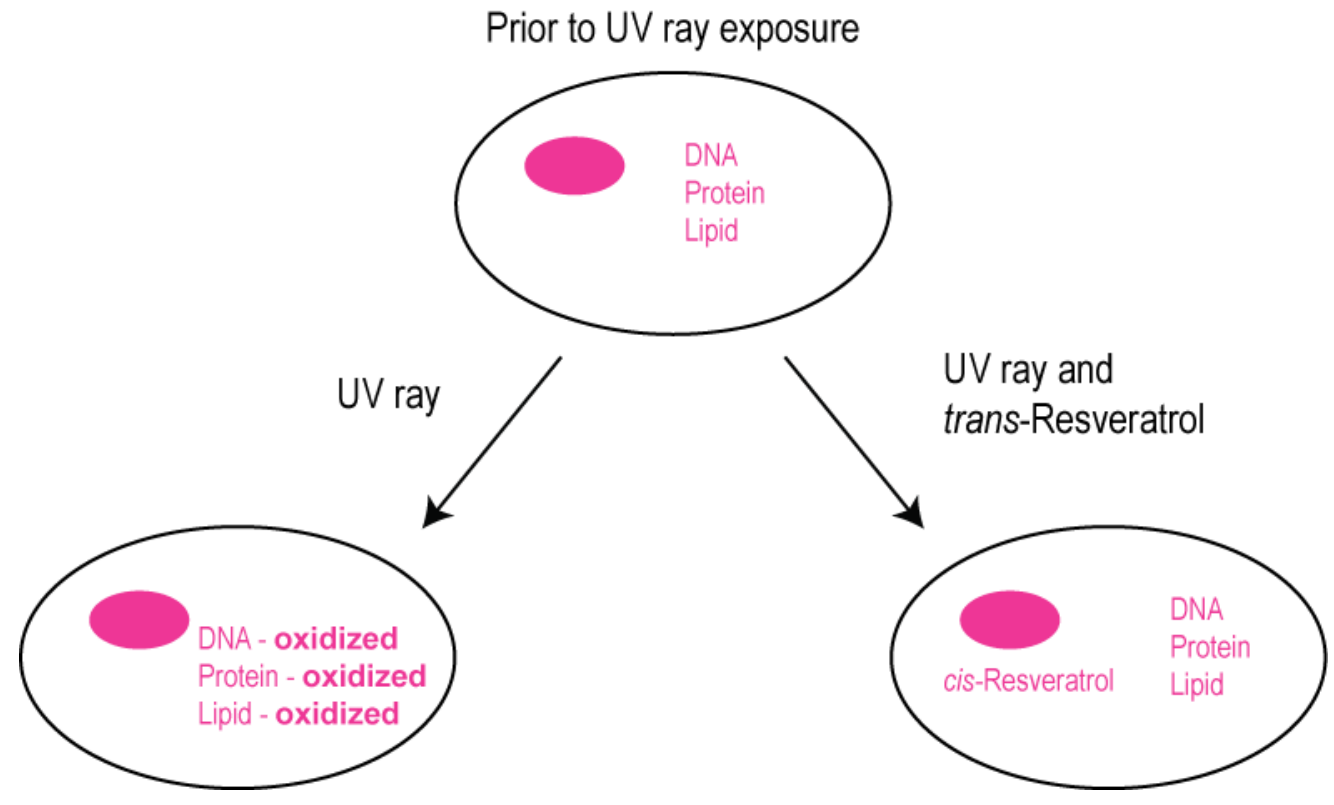

\section{Therapeutic Potential of Resveratrol via the Modulation of Cellular Calcium Signaling}

\subsection{Intracellular Calcium Channels}

Two main types of intracellular calcium channels (ICC), inositol 1,4,5-trisphosphate receptors $\left(\mathrm{IP}_{3} \mathrm{Rs}\right)$ and ryanodine receptors (RyRs), are vital for the release of calcium from the endoplasmic and sarcoplasmic reticulum (ER \& SR). Release of intracellular calcium through IP3Rs increases the intracellular calcium concentration which in turn activates RyRs to amplify the calcium signal - a process termed calcium induced calcium release (CICR). ICCs are involved in fundamental cellular processes such as cell proliferation, signaling, excitability, gene expression, and apoptosis [66]. Thus, ICCs are considered a potential target for neuroprotective and cytoprotective strategies for a number of pathologies $[28,66,67]$ although, to date, no studies have been targeted at identifying the specific 
effects of resveratrol on ICCs (Table 1). Understanding the potential effects of resveratrol on ICCs could identify novel treatment strategies for neurodegenerative diseases such as Alzheimer's disease (AD), Huntington's disease (HD), amyotrophic lateral sclerosis (ALS), and other neurodegenerative diseases.

\subsection{Store-Operated Calcium Channel}

Calcium-release activated channels (CRACs) are store-operated calcium channels located at the plasma membrane that are activated by low intracellular calcium store concentrations, resulting in a sustained increase of the cytosolic calcium concentration. Immune cells rely on this mechanism and CRACs are potential drug targets for anti-inflammatory diseases [68]. Resveratrol has not been shown to exert a direct effect on CRAC channels [69] (Table 1) although it has been suggested that resveratrol acts indirectly on store-operated calcium entry (SOCE). However, the potency of resveratrol stimulation on CRAC is far lower than that of other known neuroprotective and neuromodulatory compounds including nonsteroidal estrogens [33].

\subsection{Voltage-Gated Calcium Channels}

Plasma membrane voltage-gated calcium channels (VGCCs) are classified into high or low voltage-activated channels. VGCCs are activated by a depolarization of the membrane potential and allow extracellular calcium flux into the cytosol, thereby translating an electric signal into a secondary chemical signal. The class of high VGCCs include $\mathrm{Ca}_{\mathrm{V}} 1$ (L-type) and $\mathrm{Ca}_{\mathrm{V}} 2$ (P/Q-, N-, and R-type) channels. The low VGCCs includes $\mathrm{Ca}_{\mathrm{v}} 3$ (T-type) channels. $\mathrm{Ca}_{\mathrm{v}} 1, \mathrm{Ca}_{\mathrm{v}} 2$, and $\mathrm{Ca}_{\mathrm{v}} 3$ have slow, intermediate, and fast inactivation responses, respectively. In excitatory cells, resveratrol decreases cellular excitability by attenuating calcium influx through VGCCs [70]. Diseases related to VGCC dysregulation include neurodegenerative disorders such as $\mathrm{AD}, \mathrm{PD}$, cerebral ischemia, cardiovascular diseases, chronic and acute inflammatory diseases, many cancers, and even mood disorders [28,45,71]. The primary mechanism of action of how VGCC dysregulation leads to these disorders is hyperexcitability resulting in a chronic increase in the cytosolic calcium concentration. Therefore, VGCCs, especially the slow inactivating Cav1 channels, have become a focus of neuroprotective strategies [28,72]. Resveratrol has been shown to dose-dependently inhibit both L-type and T-type calcium channels and to increase the time period for reactivation [29]. More specifically, resveratrol inhibits L-type currents during phase 2 of an action potential, leading to vasorelaxation [26]. Also, it has been suggested that resveratrol-induced vasorelaxation is partially due to a stimulation of NOS and the ensuing chronic increase of the nitric oxide concentration [30,41].

\subsection{Calcium-Activated Potassium Channels}

Calcium-activated potassium $\left(\mathrm{K}_{\mathrm{Ca}}\right)$ channels include three major types of channels- large $(\mathrm{BK})$, intermediate $(\mathrm{IK})$, and small conductance $(\mathrm{SK})$ channels. $\mathrm{K}_{\mathrm{Ca}}$ channels help regulate the action potential activity of excitable cells via the modulation of membrane hyperpolarization. These channels play a critical role in restricting calcium influx [73]. Resveratrol does not appear to act directly on $\mathrm{K}_{\mathrm{Ca}}$ channels but rather exerts its effects through other types of calcium channels. This higher level regulation of calcium homeostasis in turn indirectly regulates potassium flux $[19,47,74]$. While there is 
no general consensus, most studies suggest that the modulation of $\mathrm{K}_{\mathrm{Ca}}$ channels by resveratrol's inhibitory effects illustrates an indirect partial reduction of potassium efflux due to moderation of calcium influx $[9,75]$.

Table 1. Resveratrol's interactions with cellular proteins and its effects on components of the cellular calcium signaling machinery.

\begin{tabular}{|c|c|c|c|}
\hline Protein & Modulatory Action & Therapeutic Application & References \\
\hline $\begin{array}{l}\text { Intracellular calcium } \\
\text { channels }\end{array}$ & TBD & $\begin{array}{l}\text { Potential for excitatory neuronal, } \\
\text { cardiac, inflammatory and } \\
\text { autoimmune diseases }\end{array}$ & --- \\
\hline $\begin{array}{l}\text { Calcium-release } \\
\text { activated channels }\end{array}$ & No direct effects & No direct disease amelioration & [60] \\
\hline $\begin{array}{l}\text { Store-operated } \\
\text { calcium entry }\end{array}$ & $\begin{array}{l}\text { Activation of store-operated } \\
\text { calcium entry }\end{array}$ & $\begin{array}{l}\text { Diseases of prolonged calcium } \\
\text { influx such as immune and } \\
\text { inflammatory diseases }\end{array}$ & [33] \\
\hline $\begin{array}{l}\text { Voltage-gated } \\
\text { calcium channels }\end{array}$ & $\begin{array}{l}\text { Dose-dependent inhibition } \\
\text { of L- and T-type channels }\end{array}$ & Prevention of uncontrolled excitability & {$[26,27]$} \\
\hline $\begin{array}{l}\text { Calcium-activated } \\
\text { potassium channels }\end{array}$ & $\begin{array}{l}\text { Indirect inhibition, likely via } \\
\text { modulation of voltage-gated } \\
\text { calcium channels }\end{array}$ & $\begin{array}{l}\text { Modulation of action potentials } \\
\text { (particularly in cardiac and } \\
\text { neurological disorders) }\end{array}$ & {$[19,47,74]$} \\
\hline SERCA & $\begin{array}{l}\text { Indirect up-regulation via } \\
\text { SIRT1 activation }\end{array}$ & $\begin{array}{l}\text { SIRT1 down regulation disorders, } \\
\text { cancer }\end{array}$ & {$[26,27]$} \\
\hline PMCA & $\begin{array}{l}\text { Indirect PMCA degradation } \\
\text { via calpain activation }\end{array}$ & Cancer & [27] \\
\hline
\end{tabular}

\subsection{SERCA and PMCA}

Calcium ATPases are calcium transport proteins that return the cellular calcium concentrations back to the transmembrane electrochemical gradient state prior to renewed depolarization. The two key proteins that mediate this mechanism are the plasma membrane calcium ATPase (PMCA), which pumps calcium out of the cell when present in high concentrations, and the SR calcium ATPase (SERCA), which replenishes the SR calcium store from the cytoplasm. To our knowledge there is no study investigating potential effects of resveratrol on PMCA. However, it appears that resveratrol upregulates SERCA via SIRT1 activation, further replenishing calcium stores and reducing intracellular calcium influx [62]. Resveratrol may prove useful to attenuate diseases related to SIRT1 downregulation [26]. Additionally, resveratrol facilitates apoptosis in cancerous cells by induction of a calpain-dependent PMCA degradation mechanism. This strategy may be further elucidated through experiments targeted at identifying resveratrol's mechanism of action in tumor cells [27].

\subsection{Mitochondrial Calcium Signaling}

Mitochondria are temporary and rapidly releasing calcium stores, capable of generating calcium spikes or waves to trigger second messenger systems. Mitochondria are critical initiators of apoptotic pathways via calcium signaling. Resveratrol has been shown to induce mitochondrial apoptosis by alteration of the mitochondrial membrane potential and eliciting a mitochondrial permeability 
transition (MPT) pore by lowering the calcium threshold necessary for MPT opening $[27,55,76]$. This mechanism is currently intensively investigated as a potential for anti-cancer drug therapy [77,78]. For instance, it has been proposed that resveratrol can induce this apoptosis in cancerous cells due to differences in mitochondrial function and that it can be injected directly into a tumor mass to initiate tumor regression prior to resection [79].

\section{Conclusions}

Resveratrol is a potent modulator of many cellular calcium signaling pathways (Table 1). The number of different targets for modulation by resveratrol (Table 1) confound the interpretation of in vivo analyses and result in cell type- and organism-specific responses. While L-type and T-type VGCCs have been identified as direct targets of resveratrol modulation, further studies are required to identify the effects on intracellular calcium channels and other neurotransmitter receptor systems. Yet there is significant evidence to suggest that the beneficial effects of resveratrol cannot be attributed only to its immunomodulatory function but also to a resveratrol dependent lowering of membrane hyperexcitability and cellular calcium toxicity. Thus resveratrol bears great promise for a number of multifactorial pathologies including neurodegeneration, autoimmune and cardiovascular disease, and cancer. Further, resveratrol as should be considered both an immunomodulator and a modulator of intracellular calcium signaling.

\section{Acknowledgments}

This publication was supported in part NIH grants EY014227, EY022774, AG010485, AG022550, and AG027956 and RR027093 (PK). The content is solely the responsibility of the authors and does not necessarily represent the official views of the National Institutes of Health. Additional support by the Felix and Carmen Sabates Missouri Endowed Chair in Vision Research, a Challenge Grant from Research to Prevent Blindness, and the Vision Research Foundation of Kansas City (PK) is gratefully acknowledged. The authors thank Margaret, Richard and Sara Koulen for generous support and encouragement.

\section{Author Contributions}

All authors have performed bibliographic searches, have written and reviewed the manuscript.

\section{Conflicts of Interest}

The authors declare no conflict of interest.

\section{References}

1. Jeandet, P.; Delaunois, B.; Conreux, A.; Donnez, D.; Nuzzo, V.; Cordelier, S.; Clément, C.; Courot, E. Biosynthesis, metabolism, molecular engineering and biological functions of stilbene phytoalexins in plants. BioFactors 2010, 36, 331-341.

2. Jeandet, P.; Clément, C.; Courot, E.; Cordelier, S. Modulation of phytoalexin biosynthesis in engineered plants for disease resistance. Int. J. Mol. Sci. 2013, 14, 14136-14170. 
3. Neves, A.R.; Lucio, M.; Lima, J.L.; Reis, S. Resveratrol in medicinal chemistry: A critical review of its pharmacokinetics, drug-delivery, and membrane interactions. Curr. Med. Chem. 2012, 19, 1663-1681.

4. Richard, J.L. Coronary risk factors. The French paradox. Arch. Mal. Coeur Vaiss. 1987, 80, 17-21.

5. St Leger, A.S.; Cochrane, A.L.; Moore, F. Factors associated with cardiac mortality in developed countries with particular reference to the consumption of wine. Lancet 1979, 1, 1017-1020.

6. Criqui, M.H.; Ringel, B.L. Does diet or alcohol explain the French paradox? Lancet 1994, 344, 1719-1723.

7. Kroon, P.A.; Iyer, A.; Chunduri, P.; Chan, V.; Brown, L. The cardiovascular nutrapharmacology of resveratrol: Pharmacokinetics, molecular mechanisms and therapeutic potential. Curr. Med. Chem. 2010, 17, 2442-2455.

8. Bagatini, P.B.; Saur, L.; Rodrigues, M.F.; Bernardino, G.C.; Paim, M.F.; Coelho, G.P.; Silva, D.V.; de Oliveira, R.M.; Schirmer, H.; Souto, A.A.; et al. The role of calcium channel blockers and resveratrol in the prevention of paraquat-induced parkinsonism in Drosophila melanogaster: A locomotor analysis. Invertebr. Neurosci. 2011, 11, 43-51.

9. Granados-Soto, V.; Arguelles, C.F.; Ortiz, M.I. The peripheral antinociceptive effect of resveratrol is associated with activation of potassium channels. Neuropharmacology 2002, 43, 917-923.

10. Park, S.J.; Ahmad, F.; Philp, A.; Baar, K.; Williams, T.; Luo, H.; Ke, H.; Rehmann, H.; Taussig, R.; Brown, A.L.; et al. Resveratrol ameliorates aging-related metabolic phenotypes by inhibiting cAMP phosphodiesterases. Cell 2012, 148, 421-433.

11. Athar, M.; Back, J.H.; Tang, X.; Kim, K.H.; Kopelovich, L.; Bickers, D.R.; Kim, A.L. Resveratrol: A review of preclinical studies for human cancer prevention. Toxicol. Appl. Pharm. 2007, 224, 274-283.

12. Yuan, M.; Li, J.; Lv, J.; Mo, X.; Yang, C.; Chen, X.; Liu, Z.; Liu, J. Polydatin (PD) inhibits IgE-mediated passive cutaneous anaphylaxis in mice by stabilizing mast cells through modulating $\mathrm{Ca}(2)(+)$ mobilization. Toxicol. Appl. Pharm. 2012, 264, 462-469.

13. Venkatesan, B.; Valente, A.J.; Reddy, V.S.; Siwik, D.A.; Chandrasekar, B. Resveratrol blocks interleukin-18-EMMPRIN cross-regulation and smooth muscle cell migration. Am. J. Physiol. Heart Circ. Physiol. 2009, 297, H874-H886.

14. Naylor, J.; Al-Shawaf, E.; McKeown, L.; Manna, P.T.; Porter, K.E.; O’Regan, D.; Muraki, K.; Beech, D.J. TRPC5 channel sensitivities to antioxidants and hydroxylated stilbenes. J. Biol. Chem. 2011, 286, 5078-5086.

15. Wang, Q.; Xu, J.; Rottinghaus, G.E.; Simonyi, A.; Lubahn, D.; Sun, G.Y.; Sun, A.Y. Resveratrol protects against global cerebral ischemic injury in gerbils. Brain Res. 2002, 958, 439-447.

16. Zhang, H.; Schools, G.P.; Lei, T.; Wang, W.; Kimelberg, H.K.; Zhou, M. Resveratrol attenuates early pyramidal neuron excitability impairment and death in acute rat hippocampal slices caused by oxygen-glucose deprivation. Exp. Neurol. 2008, 212, 44-52.

17. Chen, W.P.; Su, M.J.; Hung, L.M. In vitro electrophysiological mechanisms for antiarrhythmic efficacy of resveratrol, a red wine antioxidant. Eur. J. Pharmacol. 2007, 554, 196-204. 
18. Chen, Y.R.; Yi, F.F.; Li, X.Y.; Wang, C.Y.; Chen, L.; Yang, X.C.; Su, P.X.; Cai, J. Resveratrol attenuates ventricular arrhythmias and improves the long-term survival in rats with myocardial infarction. Cardiovasc. Drug. Ther. 2008, 22, 479-485.

19. Calderone, V.; Martelli, A.; Testai, L.; Martinotti, E.; Breschi, M.C. Functional contribution of the endothelial component to the vasorelaxing effect of resveratrol and NS 1619, activators of the large-conductance calcium-activated potassium channels. Naunyn-Schmiedeberg's Arch. Pharm. 2007, 375, 73-80.

20. Gojkovic-Bukarica, L.; Novakovic, A.; Kanjuh, V.; Bumbasirevic, M.; Lesic, A.; Heinle, H. A role of ion channels in the endothelium-independent relaxation of rat mesenteric artery induced by resveratrol. J. Pharmacol. Sci. 2008, 108, 124-130.

21. Gao, X.; Xu, Y.X.; Janakiraman, N.; Chapman, R.A.; Gautam, S.C. Immunomodulatory activity of resveratrol: Suppression of lymphocyte proliferation, development of cell-mediated cytotoxicity, and cytokine production. Biochem. Pharmacol. 2001, 62, 1299-1308.

22. Sharma, S.; Anjaneyulu, M.; Kulkarni, S.K.; Chopra, K. Resveratrol, a polyphenolic phytoalexin, attenuates diabetic nephropathy in rats. Pharmacology 2006, 76, 69-75.

23. Sheu, S.J.; Wu, T.T. Resveratrol protects against ultraviolet A-mediated inhibition of the phagocytic function of human retinal pigment epithelial cells via large-conductance calciumactivated potassium channels. Kaohsiung J. Med. Sci. 2009, 25, 381-388.

24. Sheu, S.J.; Bee, Y.S.; Chen, C.H. Resveratrol and large-conductance calcium-activated potassium channels in the protection of human retinal pigment epithelial cells. J. Ocul. Pharmacol. 2008, 24, 551-555.

25. Pirola, L.; Frojdo, S. Resveratrol: One molecule, many targets. IUBMB Life 2008, 60, 323-332.

26. Sulaiman, M.; Matta, M.J.; Sunderesan, N.R.; Gupta, M.P.; Periasamy, M.; Gupta, M. Resveratrol, an activator of SIRT1, upregulates sarcoplasmic calcium ATPase and improves cardiac function in diabetic cardiomyopathy. Am. J. Physiol. Heart Circ. Physiol. 2010, 298, H833-H843.

27. Sareen, D.; Darjatmoko, S.R.; Albert, D.M.; Polans, A.S. Mitochondria, calcium, and calpain are key mediators of resveratrol-induced apoptosis in breast cancer. Mol. Pharmacol. 2007, 72, $1466-1475$.

28. Duncan, R.S.; Goad, D.L.; Grillo, M.A.; Kaja, S.; Payne, A.J.; Koulen, P. Control of intracellular calcium signaling as a neuroprotective strategy. Molecules 2010, 15, 1168-1195.

29. Jakab, M.; Lach, S.; Bacova, Z.; Langeluddecke, C.; Strbak, V.; Schmidt, S.; Iglseder, E.; Paulmichl, M.; Geibel, J.; Ritter, M. Resveratrol inhibits electrical activity and insulin release from insulinoma cells by block of voltage-gated $\mathrm{Ca}^{+}$channels and swelling-dependent Cl- currents. Cell Physiol. Biochem. 2008, 22, 567-578.

30. Zhang, L.P.; Yin, J.X.; Liu, Z.; Zhang, Y.; Wang, Q.S.; Zhao, J. Effect of resveratrol on L-type calcium current in rat ventricular myocytes. Acta Pharmacol. Sin. 2006, 27, 179-183.

31. Dobrydneva, Y.; Williams, R.L.; Blackmore, P.F. trans-Resveratrol inhibits calcium influx in thrombin-stimulated human platelets. Br. J. Pharmacol. 1999, 128, 149-157.

32. Tian, X.M.; Zhang, Z.X. [Resveratrol promote permeability transition pore opening mediated by Ca2+]. Yao Хие Хие Ваo 2003, 38, 81-84. 
33. Dobrydneva, Y.; Williams, R.L.; Blackmore, P.F. Diethylstilbestrol and other nonsteroidal estrogens: Novel class of store-operated calcium channel modulators. J. Cardiovasc. Pharmacol. 2010, 55, 522-530.

34. Dobrydneva, Y.; Williams, R.L.; Katzenellenbogen, J.A.; Ratz, P.H.; Blackmore, P.F. Diethylstilbestrol and tetrahydrochrysenes are calcium channel blockers in human platelets: Relationship to the stilbene pharmacophore. Thromb. Res. 2003, 110, 23-31.

35. Wang, L.; Ma, Q.; Chen, X.; Sha, H.; Ma, Z. Effects of resveratrol on calcium regulation in rats with severe acute pancreatitis. Eur. J. Pharmacol. 2008, 580, 271-276.

36. Buluc, M.; Demirel-Yilmaz, E. Resveratrol decreases calcium sensitivity of vascular smooth muscle and enhances cytosolic calcium increase in endothelium. Vascul. Pharmacol. 2006, 44, 231-237.

37. Campos-Toimil, M.; Elies, J.; Alvarez, E.; Verde, I.; Orallo, F. Effects of trans- and cis-resveratrol on $\mathrm{Ca}^{2+}$ handling in A7r5 vascular myocytes. Eur. J. Pharmacol. 2007, 577, 91-99.

38. Sangeetha, M.K.; Eazhisai Vallabi, D.; Sali, V.K.; Thanka, J.; Vasanthi, H.R. Sub-acute toxicity profile of a modified resveratrol supplement. Food Chem. Toxicol. 2013, 59, 492-500.

39. Cottart, C.H.; Nivet-Antoine, V.; Beaudeux, J.L. Review of recent data on the metabolism, biological effects, and toxicity of resveratrol in humans. Mol. Nutr. Food Res. 2013, 58, 7-21.

40. Zhang, L.P.; Ma, H.J.; Zhao, J.; Wang, Q.S. Effects of resveratrol on delayed afterdepolarization and triggered activity induced by ouabain in guinea pig papillary muscles. Sheng Li Xue Bao 2005, 57, 361-366.

41. Liu, Z.; Zhang, L.P.; Ma, H.J.; Wang, C.; Li, M.; Wang, Q.S. Resveratrol reduces intracellular free calcium concentration in rat ventricular myocytes. Sheng Li Xue Bao 2005, 57, 599-604.

42. Campos-Toimil, M.; Elies, J.; Orallo, F. Trans- and cis-resveratrol increase cytoplasmic calcium levels in A7r5 vascular smooth muscle cells. Mol. Nutr. Food Res. 2005, 49, 396-404.

43. Li, H.; Xia, N.; Forstermann, U. Cardiovascular effects and molecular targets of resveratrol. Nitric Oxide 2012, 26, 102-110.

44. Baur, J.A.; Sinclair, D.A. Therapeutic potential of resveratrol: The in vivo evidence. Nat. Rev. Drug Discovery 2006, 5, 493-506.

45. Elíes, J.; Cuíñas, A.; García-Morales, V.; Orallo, F.; Campos-Toimil, M. Trans-resveratrol simultaneously increases cytoplasmic $\mathrm{Ca}^{2+}$ levels and nitric oxide release in human endothelial cells. Mol. Nutr. Food Res. 2011, 55, 1237-1248.

46. Protic, D.; Beleslin-Cokic, B.; Novakovic, R.; Kanjuh, V.; Heinle, H.; Scepanovic, R.; Gojkovic-Bukarica, L. Effect of Wine Polyphenol Resveratrol on the Contractions Elicited Electrically or by Norepinephrine in the Rat Portal Vein. Phytother. Res. 2013, 27, 1685-1693.

47. Novakovic, A.; Bukarica, L.G.; Kanjuh, V.; Heinle, H. Potassium channels-mediated vasorelaxation of rat aorta induced by resveratrol. Basic Clin. Pharmacol. Toxicol. 2006, 99, 360-364.

48. Su, H.C.; Hung, L.M.; Chen, J.K. Resveratrol, a red wine antioxidant, possesses an insulin-like effect in streptozotocin-induced diabetic rats. Am. J. Physiol. Endocrinol. Metab. 2006, 290, 1339-1346.

49. Raval, A.P.; Dave, K.R.; Perez-Pinzon, M.A. Resveratrol mimics ischemic preconditioning in the brain. J. Cereb. Blood Flow Metab. 2006, 26, 1141-1147. 
50. Raval, A.P.; Lin, H.W.; Dave, K.R.; Defazio, R.A.; Della Morte, D.; Kim, E.J.; Perez-Pinzon, M.A. Resveratrol and ischemic preconditioning in the brain. Curr. Med. Chem. 2008, 15, 1545-1551.

51. Li, M.; Wang, Q.S.; Chen, Y.; Wang, Z.M.; Liu, Z.; Guo, S.M. Resveratrol inhibits neuronal discharges in rat hippocampal CA1 area. Sheng Li Xue Bao 2005, 57, 355-360.

52. Kundu, J.K.; Surh, Y.J. Cancer chemopreventive and therapeutic potential of resveratrol: Mechanistic perspectives. Cancer Lett. 2008, 269, 243-261.

53. Le Ferrec, E.; Lagadic-Gossmann, D.; Rauch, C.; Bardiau, C.; Maheo, K.; Massiere, F.; le Vee, M.; Guillouzo, A.; Morel, F. Transcriptional induction of CYP1A1 by oltipraz in human Caco-2 cells is aryl hydrocarbon receptor- and calcium-dependent. J. Biol. Chem. 2002, 277, 24780-24787.

54. Chen, Y.F.; Chen, Y.T.; Chiu, W.T.; Shen, M.R. Remodeling of calcium signaling in tumor progression. J. Biomed. Sci. 2013, 20, doi:10.1186/1423-0127-20-23.

55. Ma, X.; Tian, X.; Huang, X.; Yan, F.; Qiao, D. Resveratrol-induced mitochondrial dysfunction and apoptosis are associated with $\mathrm{Ca}^{2+}$ and mCICR-mediated MPT activation in HepG2 cells. Mol. Cell. Biochem. 2007, 302, 99-109.

56. Yang, Y.; Paik, J.H.; Cho, D.; Cho, J.A.; Kim, C.W. Resveratrol induces the suppression of tumor-derived CD4+CD25+ regulatory T cells. Int. Immunopharmacol. 2008, 8, 542-547.

57. Bishayee, A. Cancer prevention and treatment with resveratrol: From rodent studies to clinical trials. Cancer Prev. Res. 2009, 2, 409-418.

58. Feng, Y.H.; Zhou, W.L.; Wu, Q.L.; Li, X.Y.; Zhao, W.M.; Zou, J.P. Low dose of resveratrol enhanced immune response of mice. Acta Pharmacol. Sin. 2002, 23, 893-897.

59. Falchetti, R.; Fuggetta, M.P.; Lanzilli, G.; Tricarico, M.; Ravagnan, G. Effects of resveratrol on human immune cell function. Life Sci. 2001, 70, 81-96.

60. Shin, D.H.; Seo, E.Y.; Pang, B.; Nam, J.H.; Kim, H.S.; Kim, W.K.; Kim, S.J. Inhibition of $\mathrm{Ca}^{2+}$-release-activated $\mathrm{Ca}^{2+}$ channel $(\mathrm{CRAC})$ and $\mathrm{K}^{+}$channels by curcumin in Jurkat-T cells. J. Pharmacol. Sci. 2011, 115, 144-154.

61. Singh, N.P.; Hegde, V.L.; Hofseth, L.J.; Nagarkatti, M.; Nagarkatti, P. Resveratrol (trans-3,5,4'trihydroxystilbene) ameliorates experimental allergic encephalomyelitis, primarily via induction of apoptosis in $\mathrm{T}$ cells involving activation of aryl hydrocarbon receptor and estrogen receptor. Mol. Pharmacol. 2007, 72, 1508-1521.

62. Nour, V.; Trandafir, I.; Muntean, C. Ultraviolet irradiation of trans-resveratrol and HPLC determination of trans-resveratrol and cis-resveratrol in Romanian red wines. J. Chromatogr. Sci. 2012, 50, 920-927.

63. Bertram, K.M.; Baglole, C.J.; Phipps, R.P.; Libby, R.T. Molecular regulation of cigarette smoke induced-oxidative stress in human retinal pigment epithelial cells: Implications for age-related macular degeneration. Am. J. Physiol. Cell Physiol. 2009, 297, C1200-C1210.

64. King, R.E.; Kent, K.D.; Bomser, J.A. Resveratrol reduces oxidation and proliferation of human retinal pigment epithelial cells via extracellular signal-regulated kinase inhibition. Chem. Biol. Interact. 2005, 151, 143-149.

65. Nagaoka, T.; Hein, T.W.; Yoshida, A.; Kuo, L. Resveratrol, a component of red wine, elicits dilation of isolated porcine retinal arterioles: Role of nitric oxide and potassium channels. Invest. Ophthalmol. Vis. Sci. 2007, 48, 4232-4239.

66. Berridge, M.J. Neuronal calcium signaling. Neuron 1998, 21, 13-26. 
67. Wehrens, X.H.; Lehnart, S.E.; Marks, A.R. Intracellular calcium release and cardiac disease. Annu. Rev. Physiol. 2005, 67, 69-98.

68. Feske, S. Calcium signalling in lymphocyte activation and disease. Nat. Rev. Immunol. 2007, 7, 690-702.

69. Dorrie, J.; Gerauer, H.; Wachter, Y.; Zunino, S.J. Resveratrol induces extensive apoptosis by depolarizing mitochondrial membranes and activating caspase-9 in acute lymphoblastic leukemia cells. Cancer Res. 2001, 61, 4731-4739.

70. Wallace, C.H.; Baczko, I.; Jones, L.; Fercho, M.; Light, P.E. Inhibition of cardiac voltage-gated sodium channels by grape polyphenols. Br. J. Pharmacol. 2006, 149, 657-665.

71. Anekonda, T.S.; Quinn, J.F.; Harris, C.; Frahler, K.; Wadsworth, T.L.; Woltjer, R.L. L-type voltage-gated calcium channel blockade with isradipine as a therapeutic strategy for Alzheimer's disease. Neurobiol. Dis. 2011, 41, 62-70.

72. Cain, S.M.; Snutch, T.P. Voltage-gated calcium channels and disease. Biofactors 2011, 37, 197-205.

73. Vergara, C.; Latorre, R.; Marrion, N.V.; Adelman, J.P. Calcium-activated potassium channels. Curr. Opin. Neurobiol. 1998, 8, 321-329.

74. Chang, Y.; Wang, S.J. Inhibitory effect of glutamate release from rat cerebrocortical nerve terminals by resveratrol. Neurochem. Int. 2009, 54, 135-141.

75. Chen, W.-P.; Chi, T.-C.; Chuang, L.-M.; Su, M.-J. Resveratrol enhances insulin secretion by blocking KATP and KV channels of beta cells. Eur. J. Pharmacol. 2007, 568, 269-277.

76. Kalra, N.; Roy, P.; Prasad, S.; Shukla, Y. Resveratrol induces apoptosis involving mitochondrial pathways in mouse skin tumorigenesis. Life Sci. 2008, 82, 348-358.

77. Sun, W.; Wang, W.; Kim, J.; Keng, P.; Yang, S.; Zhang, H.; Liu, C.; Okunieff, P.; Zhang, L. Anti-cancer effect of resveratrol is associated with induction of apoptosis via a mitochondrial pathway alignment. Adv. Exp. Med. Biol. 2008, 614, 179-186.

78. Schmidt, A.; Oberle, N.; Weiß, E.M.; Vobis, D.; Frischbutter, S.; Baumgrass, R.; Falk, C.S.; Haag, M.; Brügger, B.; Lin, H.; et al. Human regulatory $\mathrm{T}$ cells rapidly suppress $\mathrm{T}$ cell receptor-induced $\mathrm{Ca}^{2+}$, NF-kappaB, and NFAT signaling in conventional T cells. Sci. Signal. 2011, 4, doi:10.1126/scisignal.2002179.

79. Qureshi, A.A.; Guan, X.Q.; Reis, J.C.; Papasian, C.J.; Jabre, S.; Morrison, D.C.; Qureshi, N., Inhibition of nitric oxide and inflammatory cytokines in LPS-stimulated murine macrophages by resveratrol, a potent proteasome inhibitor. Lipids Health Dis. 2012, 11, 76.

(C) 2014 by the authors; licensee MDPI, Basel, Switzerland. This article is an open access article distributed under the terms and conditions of the Creative Commons Attribution license (http://creativecommons.org/licenses/by/3.0/). 